\title{
Quantifcation of runoff as infuenced by morphometric characteristics in a rural complex catchment
}

\begin{abstract}
This study addresses the critical scientific question of assessing the relationship between morphometric features and the hydrological factors that increase the risk of flooding in Kelantan River basin, Malaysia. Two hypotheses were developed to achieve this aim, namely: the alternate hypothesis (runoff, is influenced by morphometric characteristics in the study watershed) and the null hypothesis (runoff is not influenced by morphometric characteristics). First, the watershed was delineated into four major catchments, namely: Galas, Pergau, Lebir, and Nenggiri. Next, quantitative morphometric characters such as linear aspects, areal aspects, and relief aspects were determined on each of these catchments. Furthermore, HEC-HMS and flood response analyses were employed to simulate the hydrological response of the catchments. From the results of morphometric analysis, profound spatial changes were observed between runoff features of Kelantan River and the morphometric characteristics. The length of overflow that was related to drainage density and constant channel maintenance was found to be 0.12 in Pergau, 0.04 in both Nenggiri and Lebir, and 0.03 in Galas. Drainage density as influenced by geology and vegetation density was found to be low in all the catchments (0.07-0.24). Results of hydrological response indicated that Lebir, Nenggiri, Galas, and Pergau recorded a flood response factor of $0.75,0.63,0.40$, and 0.05 , respectively. Therefore, Lebir and Nenggiri are more likely to be flooded during a rainstorm. There was no clear indication with regard to the catchment that emerged as the most prevailing in all the morphological features. Hence, the alternate hypothesis was affirmed. This study can be replicated in other catchments with different hydrologic setup.
\end{abstract}

Keyword: Morphometric parameters; Remote sensing; GIS; Runoff; HEC-HMS; Malaysia 